The Free Internet Journal for Organic Chemistry
Paper

Arkivoc 2018, part vii, 0-0 to be inserted by editorial office

\title{
Mild alkaline hydrolysis of hindered esters in non-aqueous solution
}

Vassiliki Theodorou, *a Michalis Alagiannis, Nikoleta Ntemou, Alexios Brentas, Pinelopi Voulgari, Vasiliki

Polychronidou, Marina Gogou, Marios Giannelos, and Konstantinos Skobridis

${ }^{a}$ Department of Chemistry, University of Ioannina, GR-451 10 loannina, Greece

Email: vtheodor@cc.uoi.gr

Dedicated to Professor Dieter Seebach on the occasion of his $80^{\text {th }}$ birthday

Received 06-29-2018

Accepted 10-08-2018

Published on line $10-27-2018$

\section{Abstract}

Sterically hindered esters of carboxylic acids, which are considered very resistant to saponification, were rapidly and efficiently saponified in a non-aqueous medium using $\mathrm{NaOH}$ in $\mathrm{MeOH} / \mathrm{CH}_{2} \mathrm{Cl}_{2}$ (1:9) at room temperature. Furthermore, this reaction protocol was extended and successfully applied to the hydrolysis of tosylates and $N$-tosyl indoles.

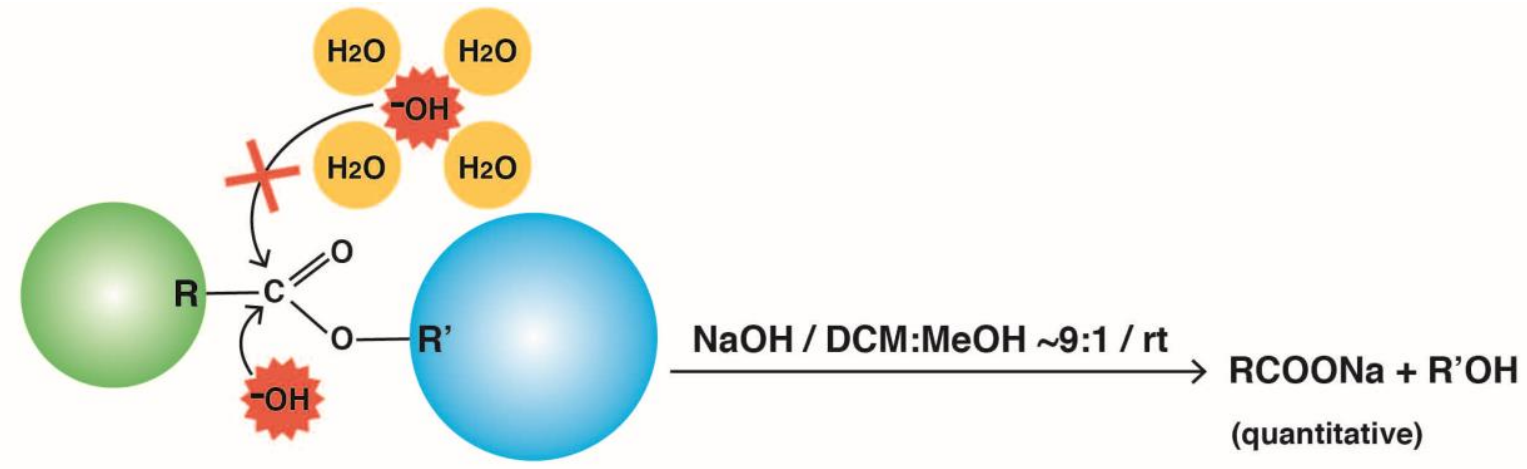

(where R and R' = bulky moieties)

Keywords: $t$-Butyl esters; non-aqueous conditions; saponification, hindered esters; tosylates; $N$-tosyl indoles 


\section{Introduction}

Alkaline hydrolysis of an ester is one of the most extensively investigated reactions. Typical methods for saponification involve the use of aqueous solutions of water-miscible solvents, large excesses of hydroxides, long reaction times, and high temperatures. The reaction rate is altered by steric and electronic effects ${ }^{1,2}$ as well as the reaction solvent ${ }^{3-5}$ due to interactions of the protic solvent with the hydroxyl anions. Solvation of the anions by water molecules through hydrogen bonding ${ }^{6-8}$ increases the energy barrier for the reactions. Replacing the traditional polar protic solvents with non-polar aprotic solvents can also exert a profound effect on the reaction rates.

The development of a mild-ester hydrolysis method is of great importance, especially in the synthesis of complex molecules, the chemistry of natural compounds, and total synthesis. A need exists for a versatile and simple process whereby esters may be hydrolysed without heating or exposure to extreme $\mathrm{pH}$ values. Crowded esters, in particular, typically afford low yields due to steric hindrance which makes carbonyl attack difficult.

In a previous work, we reported the alkaline hydrolysis of esters in non-aqueous reaction medium under very mild conditions, ${ }^{9}$ including short reaction times at room temperature, and the use of a low concentration of alkali in $\mathrm{MeOH} / \mathrm{CH}_{2} \mathrm{Cl}_{2}$ (1:9) as a solvent. We have also developed a mild protocol for the alkaline hydrolysis of secondary and tertiary amides ${ }^{10}$ to the corresponding acids and amines, while nitriles are converted to primary amides (Scheme 1).

$$
\begin{aligned}
& \mathrm{RCOOR}^{\prime}+\mathrm{NaOH} \frac{\mathrm{CH}_{2} \mathrm{Cl}_{2} / \mathrm{MeOH} \sim 9: 1}{\mathrm{rt}} \mathrm{RCOONa}+\mathrm{R}^{\prime} \mathrm{OH} \\
& \mathrm{RCONR}_{2}^{\prime}+\mathrm{NaOH} \frac{\text { Dioxane } / \mathrm{MeOH} \sim 9: 1}{\mathrm{reflux}} \mathrm{RCOONa}+\mathrm{NHR}_{2}^{\prime} \\
& \mathrm{RCN}+\mathrm{NaOH}+\mathrm{H}_{2} \mathrm{O} \frac{\text { Dioxane } / \mathrm{MeOH} \sim 9: 1}{\mathrm{reflux}} \mathrm{RCONH}_{2}
\end{aligned}
$$

Scheme 1. Alkaline hydrolysis of esters and amides and hydration of nitriles in non-aqueous conditions.

A plausible mechanistic process was proposed ${ }^{9,10}$ based on the well-established observation that hydroxide anions, when poorly solvated, attack the carbonyl groups of the esters or of the amides much more easily than the ordinarily strongly-solvated hydroxyl anions in an aqueous environment.

This method has subsequently been used to prepare sensitive compounds in excellent yields, without racemization, isomerization or other undesirable reactions. It is worth noting also that, in some of these cases, conventional methods for hydrolysis of carboxylic esters in aqueous solution did not take place under basic conditions. ${ }^{11-19}$ Moreover, the method has been applied to the hydrolysis of several sulfonates..$^{20}$

Very recently, in an attempt to hydrolyse a methyl-ester moiety on a substrate also possessing a tert-butyl ester group using our methodology, we were surprised to find that the tert-butyl group was also removed. This observation motivated us to investigate further our reaction system, using a series of sterically-hindered carboxylic esters to extend our previously-published methodology and further demonstrate its applicability to a large number of compounds.

To the best of our knowledge, there are several reports on the alkaline hydrolysis of hindered esters in non-aqueous conditions. ${ }^{21-25}$ These include, among others, the use of potassium tert-butoxide in DMSO, ${ }^{21-22}$ the use of a $\mathrm{KOH}$ complex in the presence of a phase-transfer catalyst, ${ }^{23}$ and the transesterification of sterically-hindered steroid esters to methyl esters in $\mathrm{MeOH} / \mathrm{Et}_{3} \mathrm{~N}$ under high-pressure conditions. ${ }^{24}$ Cleavage 
of tert-butyl benzoates has been attempted with NaH in DMF or, alternatively, with KOH/THF/crown ethers at high temperature. ${ }^{25}$ The tert-butyl moiety is widely used as a valuable protecting group for acids and alcohols in organic synthesis, since tert-butyl esters are remarkably stable to basic hydrolysis, but labile to acid hydrolysis.

Herein, we report, for the first time, the applicability and potency of our method in the alkaline hydrolysis of hindered esters and tosylates with very good yields.

\section{Results and Discussion}

In order to establish our methodology, a diverse set of hindered esters was selected and submitted to saponification, including esters of crowded secondary or tertiary alcohols, some of them natural products or their derivatives. For an approximate experimental comparison, parallel reactions were performed under classical conditions using $0.3 \mathrm{~N} \mathrm{NaOH}$ in $80 \% \mathrm{MeOH} / \mathrm{H}_{2} \mathrm{O}$ at rt (Scheme 2).

$$
\mathrm{RCOOR}^{\prime} \frac{1 . \mathrm{NaOH}, \text { rt./} / \mathrm{CH}_{2} \mathrm{Cl}_{2}: \mathrm{CH}_{3} \mathrm{OH} \sim 9: 1}{2 . \mathrm{H}_{3} \mathrm{O}^{+}} \mathrm{RCOOH}+\mathrm{R}^{\prime} \mathrm{OH}
$$

Scheme 2. General reaction scheme for study of saponification of diverse hindered esters using new protocol.

The study was extended to other substrates including several tosylates which were submitted to the mildalkaline hydrolysis according to this protocol. The reaction progress was monitored by TLC. After hydrolysis, the resulting alcohol or acid or both can be recovered. The conversion reactions were nearly quantitative, as revealed by the TLC analysis, unless otherwise noted. The results are summarized in Table 1. In all cases, the reactions gave rapidly the acid and/or alcohol hydrolysis products quantitatively in high purity (isolated yields $80-96 \%$ ) by the use of $0.3 \mathrm{~N} \mathrm{NaOH}$ in $10 \% \mathrm{MeOH} / \mathrm{CH}_{2} \mathrm{Cl}_{2}$ at rt. Sodium hydroxide was used in excess, in most of the cases, in a ratio of ester/ $\mathrm{NaOH}$ of $1: 3$. By addition of the methanolic solution of $\mathrm{NaOH}$ to the ester (or other substrate) dissolved in dichloromethane, a white, finely-dispersed precipitate of sodium salt begins to form slowly and increases over time. For some entries (6, 7, 12, 14, and 15), yields were not determined (nd), as the reaction products were soluble in water and/or of not special interest. Yields are not shown in column 2 of Table 1 since our primary interest was the comparison of the reaction-completion times using both methods, as observed by TLC analysis. Obviously, the classical procedure was very much slower when the esters were sterically hindered. 
Table 1. Results of examples for the alkaline hydrolysis of hindered esters and other substrates.

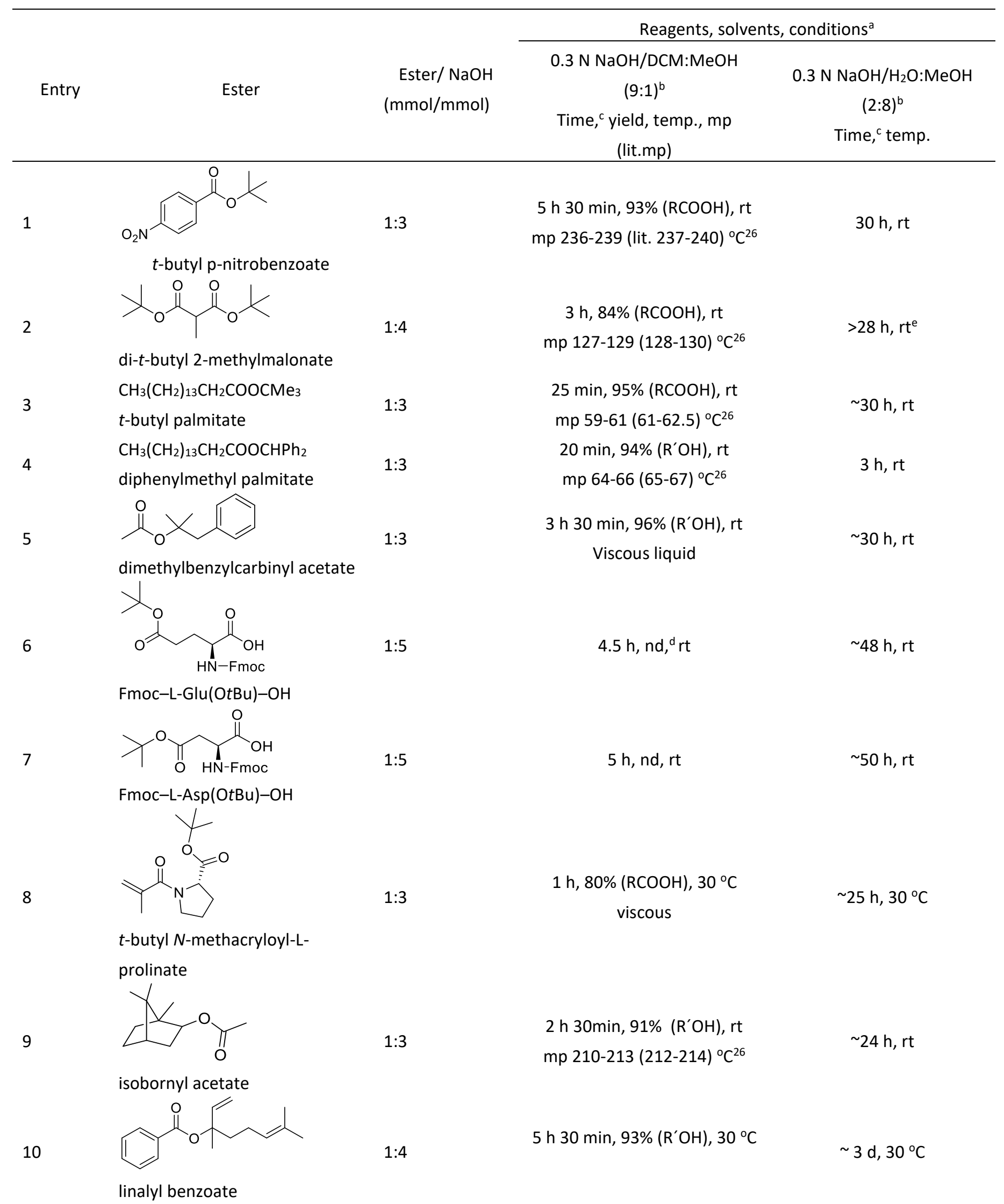


11<smiles>CC(=O)OC1CC[C@@H](C)CC1C(C)C</smiles>

(-)-menthyl acetate<smiles>CC(=O)OCC1OC(OC(C)=O)C(OC(C)=O)C(OC(C)=O)C1OC(C)=O</smiles>

$\alpha$-D(+)-glucose pentaacetate

13<smiles>Cc1ccc(S(=O)(=O)Oc2ccccc2)cc1</smiles>

phenyl tosylate<smiles>CCOS(=O)(=O)c1ccc(C)cc1</smiles>

ethyl tosylate

15<smiles>Cc1ccc(S(=O)(=O)n2cccc2)cc1</smiles>

$\mathrm{N}$-tosyl pyrrole

16<smiles>Cc1ccc(S(=O)(=O)n2ccc3ccccc32)cc1</smiles>

$\mathrm{N}$-tosyl indole<smiles>CCN(c1ccccc1)S(=O)(=O)c1ccc(C)cc1</smiles>

$\mathrm{N}$-ethyl- $\mathrm{N}$-tosyl-aniline<smiles>Cc1ccc(S(=O)(=O)Nc2ccccc2)cc1</smiles>

17

18
$45 \mathrm{~min}, 95 \%$ ( $\left.\mathrm{R}^{\prime} \mathrm{OH}\right), \mathrm{rt}$

$\mathrm{mp} 41-43(41-44){ }^{\circ} \mathrm{C}^{26}$

10-15 min, nd., rt

$21 \mathrm{~h}, \mathrm{rt}$

$3 \mathrm{~h} 45 \mathrm{~min}, 80 \%(\mathrm{PhOH})$, rt

$50 \mathrm{~min}, 30^{\circ} \mathrm{C}$

$\sim 6 \mathrm{~h}, \mathrm{nd}, 30^{\circ} \mathrm{C}$

$\sim 20 \mathrm{~h}, 30^{\circ} \mathrm{C}$

No reaction

$4 \mathrm{~h} 30 \mathrm{~min}, 82 \%$ (indole), $30{ }^{\circ} \mathrm{C}, \mathrm{mp} 50-52(51-54){ }^{\circ} \mathrm{C}^{26}$

$>24 \mathrm{~h}, 30^{\circ} \mathrm{C}^{\mathrm{e}}$

$\sim 7 \mathrm{~h}, \mathrm{nd}, 30^{\circ} \mathrm{C}$

$>30 \mathrm{~h}, 30^{\circ} \mathrm{C}^{\mathrm{e}}$

$\sim 9 \mathrm{~h}, 30^{\circ} \mathrm{C}$

$N$-tosyl-aniline

aReaction conditions: ester (1 mmol), $0.3 \mathrm{~N} \mathrm{NaOH}(3 \mathrm{mmol})$, solvent $\left(10 \mathrm{~mL}, \mathrm{CH}_{3} \mathrm{OH}: \mathrm{CH}_{2} \mathrm{Cl}_{2} 1: 9\right)$ or $\left(10 \mathrm{~mL}, \mathrm{CH}_{3} \mathrm{OH}: \mathrm{H}_{2} \mathrm{O}\right.$ 8:2). ${ }^{\text {b}}$ Each $\mathrm{mL}$ of the solution corresponds to $0.3 \mathrm{mmol}$ of $\mathrm{NaOH}$. The same volume of the solvent is used for both solvent systems. 'Monitored by TLC until the starting material was consumed. ${ }^{d}$ nd: not determined. ${ }^{e}$ Incomplete reaction ( 50\%).

It is clear from all of the examples that our hydrolysis protocol is efficient, and much faster with milder conditions than conventional methods, producing high yields of the desired products. In addition, it is particularly useful to note that the precipitated sodium carboxylates or tosylates can be easily separated by filtration or extraction. In selected cases $(\mathbf{8}, \mathbf{1 0}, \mathbf{1 3 - 1 6})$, the temperature was maintained at $\sim 30{ }^{\circ} \mathrm{C}$ to speed up slow reactions. 
The ${ }^{1} \mathrm{H}$ NMR data of the isolated hydrolysis products were identical with those of authentic samples. The disappearance of the proton peaks attributed to the acid or alcohol moieties of the ester following hydrolysis provided evidence that the hydrolysis reactions were complete. The asterisk denotes the peaks that disappear after hydrolysis (see Supplementary Material, Figure S5-S16).).

The optical purity of optically-active compounds was determined by comparison with reported values. Specific rotation and HPLC analyses have proven the lack of racemization, thus establishing the nonracemization feature of the saponification protocol (Supplementary Material, Figure S1-S4).

Specifically, the saponification of tert-butyl p-nitrobenzoate, di-tert-butyl 2-methylmalonate, the two palmitates, and dimethylbenzylcarbinyl acetate (1-5) proceeded relatively rapidly. The racemic mixtures of isobornyl acetate and linalyl benzoate $(9,10)$ were saponified after 2.5 and 5.5 hours, instead of 1 and 3 days, respectively.

The $\beta$ - and $\gamma$-tert-butyl esters of $N$-fluorenylmethyloxycarbonyl (Fmoc) amino acids $N$-Fmoc-L-glutamic and $N$-Fmoc-L-aspartic, 6 and 7, respectively (specific optical rotation for N-Fmoc-L-Glu-OH: $[\alpha]_{D}^{20}-5, c 1$ in $\mathrm{AcOH} / \mathrm{H}_{2} \mathrm{O}, 4: 1$, and for $N$-Fmoc-L-Asp-OH: $[\alpha]_{D}{ }^{20}-24, c 1$ in DMF), were hydrolysed without racemization, and with simultaneous Fmoc-deprotection (specific optical rotation for L-Glu-OH: +30 , lit. $[\alpha]_{D}{ }^{20}+31.5, c 2$ in $5 \mathrm{~N}$ $\mathrm{HCl}^{26}$ and for L-Asp-OH: +24 , lit. $[\alpha]_{\mathrm{D}}{ }^{20}+25, c 2$ in $\left.5 \mathrm{~N} \mathrm{HCl}\right) .{ }^{26} \mathrm{HPLC}$ results (Figure S1 and S2) showed the presence of one product after the alkaline hydrolysis of both, Fmoc-L-Asp(-OtBu)-OH and Fmoc-L-Glu(-OtBu)$\mathrm{OH}$. The enantiomeric purity was determined by HPLC analysis using Chirobiotic T column (water/methanol/formic acid: 30/70/0.02, flow rate $1.0 \mathrm{~mL} / \mathrm{min}$ ). The L-Asp was eluted at $4.32 \mathrm{~min}$, while the D-Asp was eluted at $5.28 \mathrm{~min}$ (Figure S1. A. and B). The L-Glu and D-Glu were eluted at 4.23 and $5.43 \mathrm{~min}$ (Figure S2. A. and B), respectively. These results clearly suggest that their saponification took place with retention of configuration.

Importantly, $t$-butyl $\mathrm{N}$-methacryloyl-L-prolinate (8) was saponified after 1 hour to afford $\mathrm{N}$-methacryloyl-Lproline, without hydrolysis of the amide bond, instead of $25 \mathrm{~h}$ under the classical conditions. The $\mathrm{N}$ methacryloyl-L-proline had a specific rotation of -136.2 , lit. $[\alpha]_{D}{ }^{20}-137.8, c 1.2$ in chloroform, ${ }^{27}$ confirming the absence of racemization. HPLC analysis showed the presence of only one product (enantiomer) after the alkaline hydrolysis of the ester during all of the different flows (Figure S3 and S4). The ${ }^{1} \mathrm{H} N M R$ data of $N$ methacryloyl-L-proline and its $t$-butyl ester are consistent with the cis and trans isomers, existing in solution, due to restricted rotation about the amide bond, and depending on the solvent. In chloroform, the trans isomer is favored, because of the $\mathrm{\gamma}$-turn, the intramolecular $\mathrm{H}$-bonding in the acid form between the $\mathrm{CO}$ oxygen and the $\mathrm{COOH}$ hydrogen (trans $91 \%$, cis $9 \%$ ), while the cis isomer of the $t$-butyl ester increases to about 33\% (trans about 67\%), ( ${ }^{1} \mathrm{H}$ NMR spectrum, Figure $\left.\mathrm{S} 10\right)$.

The alkaline hydrolysis of optically active (-)-menthyl acetate (11) was completed in 45 minutes, instead of 24 hours under normal conditions. Based on the ${ }^{1} \mathrm{H}$ NMR spectrum (Figure S13) and the specific optical rotation of the recovered (-)-menthol $\left\{-48\right.$, lit. (-)-menthol $[\alpha]_{D}{ }^{20}-50, c 10$ in ethanol ${ }^{26}$ after hydrolysis of the (-)-menthyl acetate, it was concluded that the reaction proceeded without racemization via the $\mathrm{B}_{\mathrm{AC}} 2$ mechanism. The absolute configuration of the carbon atom bearing the $\mathrm{OH}$ group of (-)-menthol (1R, 2S, 5R) did not change to give the epimer (+)-neomenthol $(1 S, 2 S, 5 R)$, as verified by its ${ }^{1} H$ NMR spectrum, which is different from that of (+)-neomenthol. No inversion of the configuration at C-1 took place during the alkaline hydrolysis. The more characteristic proton $(\mathrm{CHOH})$ of $(+)$-neomenthol resonates at $4.10 \mathrm{ppm}$ and that of $(-)-$ menthol at $3.41 \mathrm{ppm}\left({ }^{1} \mathrm{H}\right.$ NMR spectrum, Figure $\left.\mathrm{S} 13\right)$. 
We subsequently explored the potential application of our developed protocol to peracetylated glucose ( $\alpha$-D-pentaacetyl glucose). The corresponding D-(+)-glucose was formed, quantitatively, as a mixture of $\alpha$-and $\beta$-anomers within $15 \mathrm{~min}$ at rt (12); under normal conditions, the reaction was very slow (21 h).

The above methodology was also applied to the hydrolysis of tosylates and $N$-tosyl amides ${ }^{28,29}(\mathbf{1 3 - 1 8})$, (Scheme 3, eq. 1-4).

$$
\begin{aligned}
& \mathrm{RSO}_{2} \mathrm{OR}^{\prime} \frac{1 . \mathrm{NaOH} \text {, r.t. } / \mathrm{CH}_{2} \mathrm{Cl}_{2}: \mathrm{CH}_{3} \mathrm{OH} \sim 9: 1}{\text { 2. } \mathrm{H}_{3} \mathrm{O}^{\oplus}} \mathrm{RSO}_{2} \mathrm{OH}+\mathrm{R}^{\prime} \mathrm{OH} \text { (1) }
\end{aligned}
$$

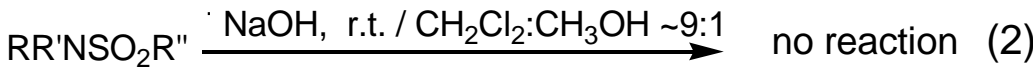

$$
\begin{aligned}
& \mathrm{RNHSO}_{2} \mathrm{R}^{\prime} \stackrel{\mathrm{NaOH} \text {, r.t. } / \mathrm{CH}_{2} \mathrm{Cl}_{2}: \mathrm{CH}_{3} \mathrm{OH} \sim 9: 1}{\longrightarrow} \mathrm{RNSO} \mathrm{P}_{2} \mathrm{R}^{\prime} \stackrel{\oplus}{\longrightarrow}+\mathrm{H}_{2} \mathrm{O} \text { (3) } \\
& \text { N-indolyl- } \mathrm{SO}_{2} \mathrm{R}^{\prime \prime} \stackrel{\mathrm{NaOH} \text {, r.t. } / \mathrm{CH}_{2} \mathrm{Cl}_{2}: \mathrm{CH}_{3} \mathrm{OH} \sim 9: 1}{\longrightarrow} \mathrm{N} \text {-indolyl-H }+\mathrm{R}^{\prime \prime} \mathrm{SO}_{2} \mathrm{ONa}(4)
\end{aligned}
$$

Scheme 3. Reactions for the alkaline hydrolysis of tosylates and $\mathrm{N}$-tosyl amides.

Indole derivatives are extensively explored molecules with significant biological activities, and a wide range of applications. For their synthesis, protection of the indole NH was necessary, followed by removal of the protective group. Sulfonamides, prepared easily with sulfonyl chloride, are between the best nitrogen protective groups. Tosyl group is one such blocking group; its deprotection usually requires harsh conditions. Introduction of a sulfonyl group on the nitrogen of pyrrole, indole and derivatives for $N$-sulfonyl protection, as well as the relatively harsh conditions of alkaline hydrolysis for $\mathrm{N}$-sulfonyl deprotection, ${ }^{30}$ encouraged us to try our alternative method. It is of interest to note that phenyl tosylate (13) was completely hydrolysed after $\sim 3.5$ $\mathrm{h}$, compared with $\sim 4 \mathrm{~d}$ using the classical methodology (and $50 \mathrm{~min}$ and $\sim 9 \mathrm{~h}$, respectively, at $30{ }^{\circ} \mathrm{C}$ ). Ethyl tosylate (14) was hydrolysed at $30^{\circ} \mathrm{C}$ after $6 \mathrm{~h}$ and $20 \mathrm{~h}$, respectively. With our protocol, $N$-tosyl pyrrole (15) and $\mathrm{N}$-tosyl indole (16) were hydrolysed after $7 \mathrm{~h}$ and $4.5 \mathrm{~h}$ at $30{ }^{\circ} \mathrm{C}$, respectively. Under normal reaction conditions, approximately $50 \%$ of the $N$-protected compounds reacted after $30 \mathrm{~h}$ and $24 \mathrm{~h}$, respectively (according to TLC). The alkaline hydrolysis of $N$-tosyl- $N$-ethylaniline (17) was impossible, even following refluxing with $0.3 \mathrm{~N} \mathrm{NaOH}$ (6 equiv.) in dioxane/methanol (9:1) for 2 days. On the other hand, $N$-tosyl-aniline (18) immediately gave the corresponding sodium salt, due to its acidic proton on $\mathrm{N}-1$. These differences in the reaction completion times are expected, due to the higher electrophilicity of the sulfonyl group of compounds 13 and 16.

Alkaline hydrolysis has been widely studied, and it is commonly accepted that the majority of the esters are saponified via a two-step $\mathrm{B}_{\mathrm{AC}} 2$ mechanism. ${ }^{31-37}$ In the non-aqueous solvent reaction, unsolvated or "naked" hydroxyl anions approach and attack the carbonyl carbon of the hindered esters much more easily than solvated ions to afford the hydrolysis products (Scheme 4). 


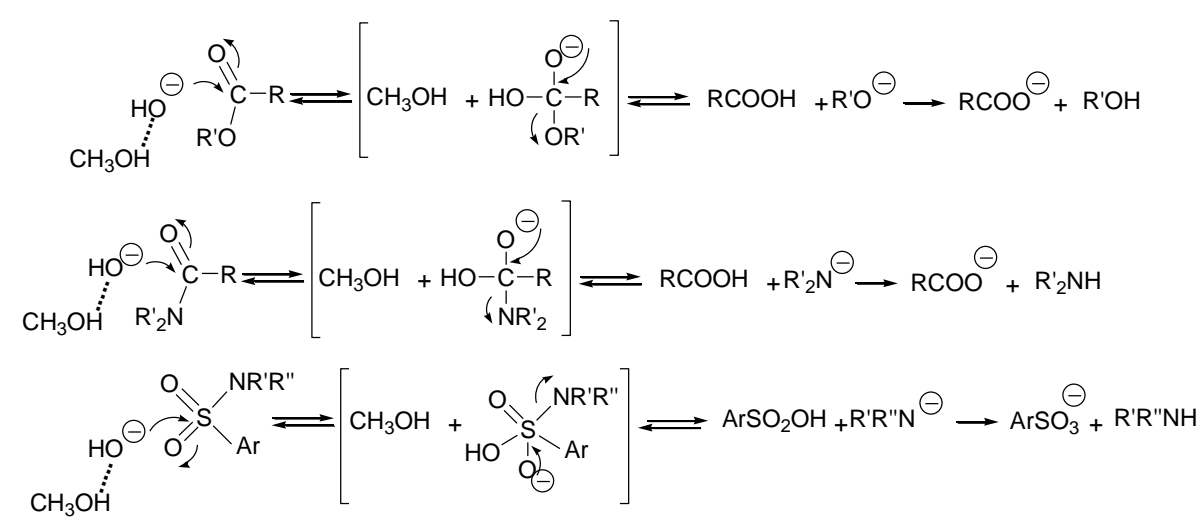

Scheme 4. Suggested mechanism for the alkaline hydrolysis in non-aqueous conditions.

\section{Conclusions}

In conclusion, our saponification methodology constitutes an advantageous mild, non-racemizing alternative to existing methods. It is shown to be available for the alkaline hydrolysis of crowded esters which are normally resistant to saponification, and for detosylation of tosylates and $\mathrm{N}$-tosyl protected pyrroles and indoles. This protocol may be useful, as well, for other substrates.

\section{Experimental Section}

General. All chemicals were obtained from commercial suppliers and used without further purification. TLC plates were from Merck Silica gel $60 \mathrm{~F}_{254}$. Optical rotations were measured on an automatic digital polarimeter. ${ }^{1} \mathrm{H}$ NMR spectra were recorded on a Bruker (AV500 MHz) at ambient temperature, using tetramethylsilane (TMS) as an internal standard. HPLC experiments were performed at $25^{\circ} \mathrm{C}$ using a Shimadzu system, consisting of a DGU-20A controller, a LC-20AD pump, a SPD-M20A photodiode-array detector and a CTO-10AS column oven, controlled with Schimadzu Class-VP, version 6, software. Elemental analyses were performed on a Heraeus CHN-Rapid Analyzer. The hydrolysis products are known compounds and were identified by comparison with authentic samples, derived from the pure products suppliers.

General experimental procedure. To a solution of the ester $(1 \mathrm{mmol})$ in $\mathrm{CH}_{2} \mathrm{Cl}_{2}(9 \mathrm{~mL})$ was added a methanolic solution of $3 \mathrm{~N} \mathrm{NaOH}(1 \mathrm{~mL}, 3 \mathrm{mmol})$, with the final concentration of the alkali being $0.3 \mathrm{~N}$, and the solvent mixture $\mathrm{CH}_{2} \mathrm{Cl}_{2} / \mathrm{CH}_{3} \mathrm{OH}(9: 1, \mathrm{v} / \mathrm{v}, 10 \mathrm{~mL})$. Esters bearing more than one ester moiety needed more equivalents of $\mathrm{NaOH}$ (Table 1). After stirring, the solution became cloudy and the sodium salt of the carboxylic acid began to precipitate. The progress of the reaction was monitored by thin layer chromatography (TLC). The mixture was stirred until the ester was consumed (Table 1), the solvents were then removed under vacuum, the residue was diluted with water $(10 \mathrm{~mL})$ and extracted with ethyl acetate or diethyl ether $(2 \times 20 \mathrm{~mL})$ to isolate the water-insoluble alcohol, and/or to remove unreacted ester. The aqueous phase was cooled, acidified to $\mathrm{pH}$ $\sim 2$ with dilute $\mathrm{HCl}$ and extracted with AcOEt $(2 \times 20 \mathrm{~mL})$. The combined organic layers were dried $\left(\mathrm{Na}_{2} \mathrm{SO}_{4}\right)$ and the solvent removed to afford the acid. Alternatively, the RCOONa precipitated during the reaction can be isolated by filtration, washed with $\mathrm{CH}_{2} \mathrm{Cl}_{2}(10 \mathrm{~mL})$, dried and weighed (Yields: 80-96\%).

Sodium palmitate precipitates after the addition of diethyl ether $(20 \mathrm{~mL})$ to the reaction mixture. 
In the case of the saponification of the Fmoc-protected amino acids \{Fmoc-Asp (O- $t$-Bu)-OH and Fmoc-Glu(O-t$\mathrm{Bu})-\mathrm{OH}$ \}, 9-methylenefluorene, derived from the Fmoc group, was extracted first with diethyl ether $(2 \times 20 \mathrm{~mL})$. The amino acid was isolated by freeze drying of the aqueous solution of its sodium salt, followed by preparative chromatographic separation of the amino acids, using a solvent mixture of 1-propanol, acetic acid and water in the ratio 12:3:5 by volume. Two additional equivalents of $\mathrm{NaOH}$ were required for hydrolysis, due to the $\mathrm{COOH}$ group and Fmoc deprotection. Increased equivalents of $\mathrm{NaOH}$ were also required with very crowded or unreactive compounds $(\mathbf{2}, \mathbf{1 0}, \mathbf{1 2}, \mathbf{1 5}$, and 16). $N$-Tosyl indole (16) gave sodium tosylate and indole. The alkaline aqueous phase was first neutralised with dilute $\mathrm{HCl}$ and then extracted with ether.

General procedure for saponification using classical conditions. To a solution of the ester ( $1 \mathrm{mmol}$ ) in $\mathrm{CH}_{3} \mathrm{OH}$ $(7 \mathrm{~mL})$ and $\mathrm{H}_{2} \mathrm{O}(2 \mathrm{~mL})$, a methanolic solution of $3 \mathrm{~N} \mathrm{NaOH}(1 \mathrm{~mL}, 3 \mathrm{mmol})$ was added with stirring; the final concentration of the alkali being $0.3 \mathrm{~N}$ and the solvent mixture $\mathrm{CH}_{3} \mathrm{OH} / \mathrm{H}_{2} \mathrm{O}(8: 2, \mathrm{v} / \mathrm{v}, 10 \mathrm{~mL})$. The progress of the reaction was monitored by TLC. The mixture was stirred until the ester was consumed (TLC) (Table 1), and then the solvents were removed under vacuum. The residue was diluted with water $(10 \mathrm{~mL})$, and subsequently extracted with ethyl acetate or diethyl ether $(2 \times 20 \mathrm{~mL})$ to isolate the water-insoluble alcohol and/or to remove unreacted ester. The aqueous phase was cooled, acidified to $\mathrm{pH} \sim 2$ with dilute $\mathrm{HCl}$ and extracted with AcOEt $(2 \times 20 \mathrm{~mL})$. The combined organic layers were dried $\left(\mathrm{Na}_{2} \mathrm{SO}_{4}\right)$ and the solvent removed to afford the acid. Yields for the resulting acids or alcohols were not determined as our interest was to measure and compare the completion times of the reactions (by TLC) of the two methodologies.

$\boldsymbol{t}$-Butyl esters syntheses. The esters 1-3 had been prepared by reaction of tert-butanol (2-4 mmol) in dry dichloromethane (DCM) $(20 \mathrm{~mL})$ and the appropriate acid chloride $(2 \mathrm{mmol})$. To the stirring mixture was added triethylamine $(5 \mathrm{mmol})$ in dry dichloromethane $(5 \mathrm{~mL})$ at $0{ }^{\circ} \mathrm{C}$ under argon. After addition was complete, the mixture was stirred for an additional 1-2 $\mathrm{h}$ at room temperature, then refluxed until completion (approximately $1 \mathrm{~h}$ ). At the end of the reaction (as determined by TLC), the reaction mixture was cooled and evaporated to dryness. The residue was diluted with $\mathrm{CH}_{2} \mathrm{Cl}_{2}$ and extracted with $\mathrm{H}_{2} \mathrm{O}, 5 \%$ $\mathrm{NaHCO}_{3}$ and $\mathrm{H}_{2} \mathrm{O}$. The organic layer was dried over $\mathrm{Na}_{2} \mathrm{SO}_{4}$, concentrated in vacuo, and purified by column chromatography $\left(\mathrm{CH}_{2} \mathrm{Cl}_{2}\right.$ /hexane) on silica to afford the desired products (overall yields $74-80 \%$ ). Their identities were confirmed by ${ }^{1} \mathrm{H}$ NMR spectroscopy.

Diphenylmethyl palmitate synthesis (4). The ester 4 has been prepared as above, from diphenyl methanol and palmitoyl chloride (Yield 75\%).

t-Butyl $\mathbf{N}$-methacryloyl-L-prolinate synthesis (8). To a solution of the methacrylic acid (2 mmol) in dry DCM $(5 \mathrm{~mL}), t$-butyl-L-prolinate $(2 \mathrm{mmol}), N, N^{\prime}$-Dicyclohexylcarbodiimide (DCC) $(2 \mathrm{mmol})$ and $\mathrm{Et}_{3} \mathrm{~N}(5$ $\mathrm{mmol}$ ) in DCM $(2 \mathrm{~mL})$ was added. The mixture was allowed to stir at $0{ }^{\circ} \mathrm{C}$ for 5 minutes. Stirring was continued overnight at $\mathrm{rt}$ until completion of the reaction (by TLC). After completion, it was concentrated to dryness. The residue was diluted with AcOEt $(50 \mathrm{~mL})$ and extracted with $\mathrm{H}_{2} \mathrm{O}(20 \mathrm{~mL})$, then with a solution of $\mathrm{NaHCO}_{3}(2 \times 15 \mathrm{~mL}), \mathrm{H}_{2} \mathrm{O}$, and finally with a solution of $\mathrm{KHSO}_{4}$. The organic layer was dried over $\mathrm{MgSO}_{4}$ and the crude product was purified by column chromatography $\left(\mathrm{CH}_{2} \mathrm{Cl}_{2} /\right.$ hexane) on silica gel. Yield: $64 \%$.

Syntheses of tosylates and $\boldsymbol{N}$-tosylamines $(13,14,17,18) \cdot{ }^{38}$ To a solution of the suitable alcohol, phenol or amine $(2 \mathrm{mmol})$ in dry DCM $(10 \mathrm{~mL})$, and cooled to $0{ }^{\circ} \mathrm{C}$, was added, portion-wise and drop-wise, 4dimethylaminopyridine $(0.4 \mathrm{mmol})$, p-toluenesulfonyl chloride $(2.4 \mathrm{mmol})$ and triethylamine $(3.00 \mathrm{mmol})$. The reaction mixture was stirred at $0{ }^{\circ} \mathrm{C}$ until TLC showed complete consumption of starting material. The resulting 
suspension was diluted with diethyl ether $(25 \mathrm{~mL})$, stirred for a further $30 \mathrm{~min}$, and the precipitate removed by filtration. The solution was then washed sequentially with water $(40 \mathrm{~mL}), 10 \% \mathrm{NaHCO}_{3}(2 \times 25 \mathrm{~mL})$ and a saturated aqueous $\mathrm{NaCl}$ solution $(10 \mathrm{~mL})$. The combined organic layers were dried over $\mathrm{MgSO}_{4}$, filtered, concentrated in vacuo, and purified by column chromatography $\left(\mathrm{CH}_{2} \mathrm{Cl}_{2} /\right.$ hexane).

Syntheses of $\boldsymbol{N}$-tosyl pyrrole and $\boldsymbol{N}$-tosyl indole $(15,16) \cdot{ }^{39}$ A mixture of the indole or the pyrrole $(1 \mathrm{mmol}), \mathrm{p}$ toluenesulfonyl chloride $(2 \mathrm{mmol}), \mathrm{K}_{2} \mathrm{CO}_{3}(4 \mathrm{mmol})$ and toluene $(15 \mathrm{~mL})$ was heated at reflux with stirring. After $15 \mathrm{~h}$, the resulting suspension was filtered hot and the solution was concentrated under reduced pressure. The residue was diluted with diethyl ether $(15 \mathrm{~mL})$ and triturated with hexane. The precipitate was removed by filtration and crystallised from EtOH-hexane to yield $85 \%$ and $75 \%$ of products 15 and $\mathbf{1 6}$, respectively.

t-Butyl p-nitrobenzoate (1). White solid (80\%, $0.36 \mathrm{~g}), \mathrm{mp} 107-108{ }^{\circ} \mathrm{C} ;{ }^{1} \mathrm{H}$ NMR $\left(\mathrm{CDCl}_{3}, 500 \mathrm{MHz}\right): \delta_{H} 1.62$ $(\mathrm{s}, 9 \mathrm{H}, t-\mathrm{Bu}), 8.14\left(\mathrm{~d}, 2 \mathrm{H}, 3^{3} \mathrm{JHH} 8.5 \mathrm{~Hz}, \mathrm{CH}\right.$ aromatic), 8.26 (d, $2 \mathrm{H},{ }^{3} \mathrm{~J}_{\mathrm{HH}} 8.5 \mathrm{~Hz}, \mathrm{CH}$ aromatic); Anal. Calcd. for $\mathrm{C}_{11} \mathrm{H}_{13} \mathrm{NO}_{4}$ : C, 59.19; $\mathrm{H}, 5.87 ; \mathrm{N}, 6.27$; found: $\mathrm{C}, 59.03 ; \mathrm{H}, 5.91 ; \mathrm{N}, 6.17 \%$.

Di-t-butyl 2-methylmalonate (2). White viscous liquid (80\%, $0.37 \mathrm{~g}) ;{ }^{1} \mathrm{H} \mathrm{NMR}\left(\mathrm{CDCl}_{3}, 500 \mathrm{MHz}\right): \delta_{\mathrm{H}} 1.32(\mathrm{~d}$, $3 \mathrm{H}, \mathrm{CHCH}_{3},{ }^{3} \mathrm{~J}_{H H} 7 \mathrm{~Hz}$ ), $1.46(\mathrm{~s}, 18 \mathrm{H}, 2 \mathrm{x}-t-\mathrm{Bu}), 3.22\left(\mathrm{q}, 1 \mathrm{H}, \mathrm{C}_{\mathbf{H C H}}{ }_{3}^{3} \mathrm{~J}_{H H} 7.0 \mathrm{~Hz}\right.$ ); Anal. Calcd. for $\mathrm{C}_{12} \mathrm{H}_{22} \mathrm{O}_{4}: \mathrm{C}_{\text {, }}$ 62.58; $\mathrm{H}, 9.63$; found: $\mathrm{C}, 62.30 ; \mathrm{H}, 9.82 \%$.

t-Butyl palmitate (3). White viscous liquid (74\%, $0.46 \mathrm{~g}) ;{ }^{1} \mathrm{H} \mathrm{NMR}\left(\mathrm{CDCl}_{3}, 500 \mathrm{MHz}\right): \delta_{\mathrm{H}} 0.88\left(\mathrm{t}, 3 \mathrm{H}, \mathrm{CH}_{3},{ }^{3} J_{H H} 7.0\right.$ $\mathrm{Hz}), 1.22-1.35\left(\mathrm{~m}, 24 \mathrm{H},\left\{\mathrm{CH}_{2}\right\}_{12}\right), 1.44(\mathrm{~s}, 9 \mathrm{H}), 1.54-1.60\left(\mathrm{~m}, 2 \mathrm{H}, \mathrm{CH}_{2} \mathrm{CH}_{2} \mathrm{COO}-t-\mathrm{Bu}\right), 2.19\left(\mathrm{t}, 2 \mathrm{H}, \mathrm{CH}_{2} \mathrm{CH}_{2} \mathrm{COO}-t-\mathrm{Bu}\right.$ J $7.5 \mathrm{~Hz}$ ); Anal. Calcd. for $\mathrm{C}_{20} \mathrm{H}_{40} \mathrm{O}_{2}$ : C, 76.86; $\mathrm{H}, 12.90$; found: C, 76.91; $\mathrm{H}, 12.78 \%$.

Diphenylmethyl palmitate (4). White viscous liquid (75\%, $0.64 \mathrm{~g}) .{ }^{1} \mathrm{H} \mathrm{NMR}\left(\mathrm{CDCl}_{3}, 500 \mathrm{MHz}\right): \delta_{\mathrm{H}} 0.88(\mathrm{t}, 3 \mathrm{H}$, $\left.\mathrm{CH}_{3},{ }^{3} J_{H H} 7.0 \mathrm{~Hz}\right), 1.20-1.35\left(\mathrm{~m}, 24 \mathrm{H},\left\{\mathrm{CH}_{2}\right\}_{12}\right), 1.62-1.69\left(\mathrm{~m}, 2 \mathrm{H}, \mathrm{CH}_{2} \mathrm{CH}_{2} \mathrm{COOAr}\right), 2.42\left(\mathrm{t}, 2 \mathrm{H}, \mathrm{CH}_{2} \mathrm{CH}_{2} \mathrm{COOAr}^{3} \mathrm{~J}_{\mathrm{HH}}\right.$ 7.5 Hz), 7.26-7.34 (m, 10H, CH aromatic); Anal. Calcd. for $\mathrm{C}_{29} \mathrm{H}_{42} \mathrm{O}_{2}$ : C, 82.41; $\mathrm{H}, 10.02$; found: $\mathrm{C}, 82.28$; $\mathrm{H}$, $9.98 \%$.

t-Butyl $\boldsymbol{N}$-methacryloyl-L-prolinate (8). White viscous liquid (64\%, $0.30 \mathrm{~g}) ;{ }^{1} \mathrm{H} \mathrm{NMR}\left(\mathrm{CDCl}_{3}, 500 \mathrm{MHz}\right): \delta_{\mathrm{H}} 1.46$ $(\mathrm{s}, 9 \mathrm{H}, t-\mathrm{Bu}), 1.80-2.20(\mathrm{~m}, 6 \mathrm{H}), 2.22-2.25(\mathrm{~m}, 1 \mathrm{H}), 3.57-3.64(\mathrm{~m}, 2 \mathrm{H}), 4.38(\mathrm{~m}, 1 \mathrm{H}), 5.05-5.27\{2 \mathrm{H}$ for two rotamers, each one pair of singlets (trans $\sim 67 \%$ and cis $\sim 33 \%)$, vinyl moiety $\left(=\mathrm{CH}_{2}\right)$ \}; Anal. Calcd. for $\mathrm{C}_{13} \mathrm{H}_{21} \mathrm{NO}_{3}$ : C, 65.25; H, 8.84; N, 5.85; found: C, 65.13; H, 8.90; N, 5.78\%.

Phenyl tosylate (13). White solid (89\%, $0.44 \mathrm{~g}), \mathrm{mp} 93-94{ }^{\circ} \mathrm{C} ;{ }^{1} \mathrm{H} \mathrm{NMR}\left(\mathrm{CDCl}_{3}, 500 \mathrm{MHz}\right): \delta_{\mathrm{H}} 2.45(\mathrm{~s}, 3 \mathrm{H}$, $\left.\mathrm{CH}_{3}\right), 6.98\left(\mathrm{~d}, 2 \mathrm{H}, \mathrm{CH}\right.$ aromatic, $\left.{ }^{3} \mathrm{~J}_{\mathrm{HH}} 8.0 \mathrm{~Hz}\right), 7.24-7.31\left(\mathrm{~m}, 5 \mathrm{H}, \mathrm{CH}\right.$ aromatic), $7.70\left(\mathrm{~d}, 2 \mathrm{H}, \mathrm{CH}\right.$ aromatic, ${ }^{3} \mathrm{~J}_{\mathrm{HH}}$ $8.0 \mathrm{~Hz}$ ); Anal. Calcd. for $\mathrm{C}_{13} \mathrm{H}_{12} \mathrm{O}_{3} \mathrm{~S}: \mathrm{C}, 62.88 ; \mathrm{H}, 4.87$; found: $\mathrm{C}, 63.05 ; \mathrm{H}, 4.72 \%$.

$\boldsymbol{N}$-tosyl-indole (16). Brown solid (85\%, $0.46 \mathrm{~g}), \mathrm{mp} 81-83{ }^{\circ} \mathrm{C}(\mathrm{EtOH} / \mathrm{hexane}) ;{ }^{1} \mathrm{H} \mathrm{NMR}\left(\mathrm{CDCl}_{3}, 500 \mathrm{MHz}\right): \delta_{\mathrm{H}}$ $2.33\left(\mathrm{~s}, 3 \mathrm{H}, \mathrm{CH}_{3}\right), 6.65\left(\mathrm{~d}, 1 \mathrm{H}, \mathrm{CH}\right.$ aromatic, $\left.{ }^{3} \mathrm{~J}_{\mathrm{HH}} 3.5 \mathrm{~Hz}\right), 7.20-7.32(\mathrm{~m}, 4 \mathrm{H}, \mathrm{CH}$ aromatic), $7.52(\mathrm{~d}, 1 \mathrm{H}, \mathrm{CH}$ aromatic, $\left.{ }^{3} J_{H H} 8.0 \mathrm{~Hz}\right), 7.56\left(\mathrm{~d}, 1 \mathrm{H}, \mathrm{CH}\right.$ aromatic, $\left.{ }^{3} \mathrm{~J}_{H H} 3.5 \mathrm{~Hz}\right), 7.76\left(\mathrm{~d}, 2 \mathrm{H}, 3^{3} \mathrm{~J}_{H H} 8.0 \mathrm{~Hz}\right), 7.99\left(\mathrm{~d}, 2 \mathrm{H},{ }^{3} \mathrm{~J}_{H H} 8.5\right.$ $\mathrm{Hz}$ ); Anal. Calcd. for $\mathrm{C}_{15} \mathrm{H}_{13} \mathrm{NO}_{2} \mathrm{~S}$ : C, 66.40; $\mathrm{H}, 4.83 ; \mathrm{N}, 5.16$; found: $\mathrm{C}, 66.26 ; \mathrm{H}, 4.89 ; \mathrm{N}, 5.10 \%$.

\section{Acknowledgements}

We are grateful to Dr. Nikitas Ragoussis (Vioryl, S.A., Greece) for providing us with samples. We thank also the NMR Center of the University of loannina for taking the ${ }^{1} \mathrm{H}$ NMR spectra. This research has been financially supported partly by the General Secretariat for Research and Technology (GSRT) and the Hellenic Foundation for Research and Innovation (HFRI) (Scholarship Code: 2000) 


\section{Supplementary Material}

Chiral HPLC analysis for hydrolysis of esters of L-amino acids and copies of ${ }^{1} \mathrm{H}$ NMR spectra of esters and corresponding hydrolysis products are provided in the online Supplementary Material file associated with this manuscript.

\section{References}

1. Wang, N.; Wang, C. H. J. Org. Chem. 1971, 36, 3178.

https://doi.org/10.1021/jo00820a021

2. Hoffman, M. K.; Berliner, E. J. J. Org. Chem. 1970, 35, 745.

https://doi.org/10.1021/jo00828a045

3. Gallagher, G. A.; Miller, J. G.; Day, A. R. J. Am. Chem. Soc. 1957, 79, 4324.

https://doi.org/10.1021/ja01573a021

4. Cramar, C.; Hawkins, C.; Truhlar, D. J. Chem. Soc. Faraday Trans. 1994, 90, 1802.

5. Xie, D.; Zhou, Y.; Xu, D.; Guo, H. Org. Lett. 2005, 7, 2093.

https://doi.org/10.1021/ol0502836

6. Matta, M. S.; Toenjes, A. A. J. Am. Chem. Soc. 1985, 107, 7591.

https://doi.org/10.1021/ja00311a062

7. Kovach, I. M.; Elrod, J. P.; Schowen, R. L. J. Am. Chem. Soc. 1980, 102, 7530.

https://doi.org/10.1021/ja00545a023

8. Haeffner, F.; Hu, C.-H.; Brinck, T.; Norin, T. J. Mol. Struct. (Theochem.) 1999, 459, 85.

https://doi.org/10.1016/S0166-1280(98)00251-6

9. Theodorou, V.; Skobridis, K.; Tzakos, A. G.; Ragoussis, V. Tetrahedron Lett. 2007, 48, 8230.

https://doi.org/10.1016/j.tetlet.2007.09.074

10. Theodorou, V.; Paraskevopoulos, G.; Skobridis, K. Arkivoc 2015 (vii) 101.

11. Ioannidou, A.; Martin, A.; Gollner, A.; Koutentis, P. J. Org. Chem. 2011, 76, 5113.

https://doi.org/10.1021/jo200824b

12. Burja, B.; Kočevar, M.; Polanc, S. Tetrahedron 2009, 65, 8690.

https://doi.org/10.1016/j.tet.2009.08.047

13. Elkady, E. F.; Fouad, M. A. Talanta, 2011, 87, 222.

https://doi.org/10.1016/j.talanta.2011.10.001

14. Akella, S. V. S.; Kirk, W. D. J.; Lu, Y.; Murai, T.; Walters, K. F. A.; Hamilton, J. G. C. Plos-One, 2014, 9, e103315.

https://doi.org/10.1371/journal.pone.0103315

15. Kotali, A.; Maniadaki, A.; Kotali, E.; Harris, P. A.; Rózycka-Sokołowska, E.; Bałczewski, P.; Joule, J. A. Synthesis 2016, 48, 4117.

https://doi.org/10.1055/s-0035-1562610

16. Csóka, T.; Nemes, A.; Szabó, D. Tetrahedron Lett. 2013, 54, 1730.

https://doi.org/10.1016/j.tetlet.2013.01.072

17. Barraza, S. J.; Delekta, P. C.; Sindac, J. A.; Dobry, C. J.; Xiang, J.; Keep, R. F.; Miller, D. J.; Larsen, S. D. Bioorg. Med. Chem. 2015, 23, 1569.

https://doi.org/10.1016/i.bmc.2015.01.054 
18. Znabet, A.; Ruijter, E.; Kanter, F. J. J.; V. Köhler, V.; Helliwell, M.; Turner N. J.; Orru, R. V. A. Angew. Chem. Int. Ed. 2010, 49, 5289.

https://doi.org/10.1002/anie.201001592

19. Kinigopoulou, M.; Filippidou, M.; Gogou, M.; Giannousi, A.; Fouka, P.; Ntemou, N.; Alivertis, D.; Georgis, C.; Brentas, A.; Polychronidou, V.; Voulgari, P.; Theodorou, V.; Skobridis, K. RSC Adv., 2016, 6, 61458. https://doi.org/10.1039/C6RA09812F

20. Miller, S. C. J. Org. Chem. 2010, 75, 4632.

\section{https://doi.org/10.1021/jo1007338}

21. Chang, F. C.; Wood, N. F. Tetrahedron Lett. 1964, 5, 2969.

https://doi.org/10.1016/0040-4039(64)83072-0

22. Gassman, P. G.; Schenk, W. N. J. Org. Chem. 1977, 42, 918.

https://doi.org/10.1021/jo00425a040

23. Pedersen, C. J. J. Am. Chem. Soc. 1967, 89, 7017.

https://doi.org/10.1021/ja01002a035

24. Kroszczynski, W.; Olszewskaa, E.; Salanski, P.; Jurczak, J. Helv. Chim. Acta, 2004, 87, 1488.

25. Fitali, E.; Lloyd-Jones, G. C.; Sale, D. A. Synlett 2009, 205.

26. Comparison with authentic samples from pure products suppliers (Aldrich).

27. Kim, B. H.; Lee, H. B.; Hwang, J. K.; Kim, Y. G. Tetrahedron: Asymmetry 2005, 16, 1215.

\section{https://doi.org/10.1016/j.tetasy.2005.01.037}

28. Greene's Protective Groups in Organic Synthesis; Wuts, P. G. M., Greene, W. T., Fourth Ed.; WileyInterscience, 1990.

29. Bajwa, J. S.; Chen, G-P.; Prasad, K.; Repic, O.; Blacklock, T. J. Tetrahedron Lett. 2006, 47, 6425.

https://doi.org/10.1016/i.tetlet.2006.06.132

30. Merrill, B. A.; LeGoff, E. J. Org. Chem. 1990, 55, 2904.

https://doi.org/10.1021/jo00296a062

31. Mata-Segreda, J. F. J. Am. Chem. Soc. 2002, 124, 2259.

https://doi.org/10.1021/ja011931t

32. Bender, M. L. Chem. Rev. 1960, 60, 53.

https://doi.org/10.1021/cr60203a005

33. Johnson, S. L. Adv. Phys. Org. Chem. 1967, 5, 237.

https://doi.org/10.1016/S0065-3160(08)60312-3

34. Jencks, W. P. Chem. Rev. 1972, 72, 705.

https://doi.org/10.1021/cr60280a004

35. O'Leary, M. H; Marlier, J. F. J. Am. Chem. Soc. 1979, 101, 3300.

https://doi.org/10.1021/ja00506a027

36. Zhan, C-G.; Landry, D. W.; Ornstein, R. L. J. Am. Chem. Soc. 2000, 122, 2621.

37. Zhan, C-G.; Landry, D. W.; Ornstein, R. L. J. Phys. Chem. A 2000, 104, 7672.

38. Dobbs, A. P.; Guesne, S. J. J.; Parker, R. J.; Skidmore, J.; Stephensond, R. A.; Hursthouse, M. B. Org. Biomol. Chem., 2010, 8, 1064.

https://doi.org/10.1039/b915797b

39. Ponticello, G. S.; Baldwin, J. J. J. Org. Chem. 1979, 44, 4003.

https://doi.org/10.1021/jo01336a065 